\title{
Telomeres and telomerase in oncogenesis (Review)
}

\author{
TOMASZ TRYBEK ${ }^{1}$, ARTUR KOWALIK ${ }^{2}$, STANISŁAW GÓŹDŹ ${ }^{3,4}$ and ALDONA KOWALSKA ${ }^{1,3}$ \\ ${ }^{1}$ Endocrinology Clinic; ${ }^{2}$ Department of Molecular Diagnostics, Holycross Cancer Center, 25-734 Kielce; \\ ${ }^{3}$ The Faculty of Health Sciences, Jan Kochanowski University, 25-319 Kielce; \\ ${ }^{4}$ Oncology Clinic, Holycross Cancer Center, 25-734 Kielce, Poland
}

Received February 24, 2020; Accepted March 25, 2020

DOI: 10.3892/ol.2020.11659

\begin{abstract}
Telomeres are located at the ends of chromosomes and protect them from degradation. Suppressing the activity of telomerase, a telomere-synthesizing enzyme, and maintaining short telomeres is a protective mechanism against cancer in humans. In most human somatic cells, the expression of telomerase reverse transcriptase (TERT) is repressed and telomerase activity is inhibited. This leads to the progressive shortening of telomeres and inhibition of cell growth in a process called replicative senescence. Most types of primary cancer exhibit telomerase activation, which allows uncontrolled cell proliferation. Previous research indicates that TERT activation also affects cancer development through activities other than the canonical function of mediating telomere elongation. Recent studies have improved the understanding of the structure and function of telomeres and telomerase as well as key mechanisms underlying the activation of TERT and its role in oncogenesis. These advances led to a search for drugs that inhibit telomerase as a target for cancer therapy. The present review article summarizes the organization and function of telomeres, their role in carcinogenesis, and advances in telomerase-targeted therapy.
\end{abstract}

\section{Contents}

\section{Introduction \\ 2. History \\ 3. Telomere structure and function \\ 4. Telomerase \\ 5. Telomeres as tumor suppressors}

6. Mechanisms activating TERT transcription and telomerase in human cancer

7. TERT promoter mutations-cancer-specific biomarkers in diagnostics/screening

Correspondence to: Dr Tomasz Trybek, Endocrinology Clinic, Holycross Cancer Center, Artwinskiego Street 3, 25-734 Kielce, Poland E-mail: trytom1@tlen.pl

Key words: telomerase, telomeres, cancer, telomerase reverse transcriptase, oncogenesis
8. TERT promoter mutations-prognostic factors in cancer/sign of aggressiveness

9. Telomere shortening in cancer and its potential advantage

10. Telomeres as a possible therapeutic target

11. Conclusions

\section{Introduction}

Cancer, the second leading cause of death globally, was responsible for an estimated 9.6 million deaths in 2018 (1). An increasing life expectancy extends the period over which oncogenes act on cells and increases the risk of cancer development. The formation and development of cancer is caused by the accumulation of genetic mutations in cells. Cancer is a genetic event in which normal cells accumulate genomic instability and acquire the ability to replicate indefinitely, which is the phenotype of immortality. Telomerase repression and/or short telomeres in human cells are suggested to be a natural evolutionary strategy in the fight against cancer; it functions as a strong barrier to tumor transformation and prevents uncontrolled cell proliferation (2). The basis of oncogenesis is the infinite proliferation of malignant cells, which in most cases is achieved by the activation of telomerase (3).

Telomeres are repeatable (TTAGGG) DNA-protein complexes that protect the ends of chromosomes. They are reduced during cell division in somatic cells. Dysfunctional telomeres may arise as a result of their critical shortening that induce a DNA damage responses (DDR) and cause cellular senescence. If the cells inherit or acquire damage to detect short telomeres they will continue to divide, and the telomeres will continue to shorten and the cells will reach the next phase called the crisis. This leads to the joining of the ends of various chromosomes, pathological mitoses, genomic instability and apoptosis. Some of the cells avoid crisis and activate the telomerase gene, telomerase reverse transcriptase (TERT), which codes for telomerase, the enzyme responsible for the synthesis of telomere. Telomerase activity allows the cancer cell to have unlimited replication. Although TERT is usually silenced in almost all somatic cells, it is significantly expressed in $85-95 \%$ of human cancers $(3,4)$. TERT expression is up-regulated in tumors via multiple genetic and epigenetic mechanisms including: TERT promoter mutations (mainly C228T or C250T), alterations in alternative splicing of TERT pre-mRNA, TERT amplification, epigenetic modifications 
through TERT promoter methylation, and/or disruption of telomere position effect (TPE) machinery (1). Rarely, another DNA recombination mechanism called alternative lengthening of telomeres (ALT) is used in $~ 5-15 \%$ of tumors mostly arising from mesenchymal or epithelial tissues (including bone, soft tissues, neuroendocrine systems, and nervous system) (5). The mechanisms that regulate TERT expression and telomerase activity are extensively studied. In addition, telomerase inhibition strategies are used to progressively shorten telomeres and ultimately kill cancer cells. Currently, many drugs that inhibit telomerase in various mechanisms are being evaluated in cancer clinical trials. We present achievements in the field of telomeres and telomerase biology, mechanisms underlying cancer and the development of cancer therapies (6).

\section{History}

In 1965,L. Hayflick showed that a human diploid cell can divide only a limited number of times (Hayflick limit-about 60 divisions) and there is a gradual inhibition of mitotic activity, called replicative sencence (7). Ołownikow associated the problem of chromosome shortening with sencence (8). Then Szostak and Blackburn (1982), Blackburn (1991) and Greider 1991) described that telomeres shortened 50-200 bp in each division until reaching the critical limit (9-11). The sequential structure of telomeres formed by 5'-TTAGGG-3' repeats and its genomic DNA protection function has been proposed by Moyzis et al (12), Makarov et al (13), Wellinger and Sen (14). In 2001, Blackburn introduced a telomeric function to maintain chromosome integrity and genome stability (15). In addition, Greider and Blackburn (16), Lendvay et al (17), Lingner and Cech (18) presented two telomerase subunits: The telomerase reverse transcriptase catalytic subunit (TERT) and the RNA template (TERC). In 2004, Liu et al (19) described that in somatic cells, telomerase remains inactive, but its activity can be found in germ cells and stem cells. In addition, reactivation of telomerase in somatic cells is one way to acquire uninhibited proliferation in cancer. Telomerase activity was detected gradually in approximately $85 \%$ of malignant tumors $(20,21)$. In 2013, the presence of C228T and C250T in the TERT promoter mutation in melanoma was reported $(22,23)$. Further studies have shown the presence of these mutations in other cancers, mainly in the central nervous system, bladder, liver, thyroid, and others, described in the following sections of the article. Recent reports explaining the reactivation of telomerase and attempts to inhibit it in malignant cells give hope for its potential use in cancer treatment.

\section{Telomere structure and function}

Telomeres are nucleoprotein structures located at the ends of chromosomes in eukaryotic cells. Each chromosome has two telomeres and there are 92 telomeres in a diploid human cell. Human telomeric DNA is composed of tandem repeats [10-15 kilobases $(\mathrm{kb})$ at birth] of double-stranded DNA nucleotide sequence 5'-TTAGGG-3', and the final 3' G-rich single-stranded overhang (150-200 nucleotide long), linked by telomere-binding proteins (TBPs) (3).

The telomere spatial structure is created from the 3 'G-rich overhang, which invades the homologous double-stranded
TTAGGG region and forms a smaller D-loop. Then the larger T-loop is built using protein protective complex called shelterin.

Shelterin has three core subunits: Telomere repeat factor (TRF)-1, TRF2, which recognize and bind duplex TTAGGG repeats, and human protection of telomeres 1 (POT1) which is responsible for recognizing single-stranded TTAGGG overhangs. These three proteins are additionally connected by: TRF1-interacting protein 2 (TIN2), TINT1/PTOP/PIP1 protein (TPP1), and repressor-activator protein 1 (Rap1) (Fig. 1).

TRF1 controls the replication of telomeric DNA, TRF2 participates in the formation of T-loops, prevents the activation of DDR pathways and non-homologous end joining (NHEJ) of telomere $(24,25)$. POT1 (in association with TPP1) combines with 3' single-stranded overhang and inhibits ATR-mediated DDR by preventing the recruitment of replication protein A (26). RAP1 affects the selective binding of TRF2 to telomeric DNA (27). TIN2 combines TRF1 and TRF2 with the TPP1/POT1 heterodimer and with telomeric DNA, improves complex stabilization (28).

The shelterin protein complex plays a fundamental role in homeostasis and telomere end stabilization, and protects chromosome ends from inappropriate DNA repair by preventing the activation of DDR pathways and non-homologous end joining (NHEJ) (29).

The basic function of telomeres is to protect the ends of chromosomes against degradation and loss of genetic information. During cell division, telomeres are shortened and do not bear genetic information essential for the cell. The process is the result of combining the phenomenon of end replication with DNA processing at the ends of chromosomes. During semiconservative replication, the delayed strand (resulting from the combination of Okazaki fragments) after the removal of the RNA primer has an incomplete 5 ' end. The resulting gap cannot be filled because the DNA polymerases responsible for the replication process synthesize the polynucleotide chain only in the $5^{\prime}$ to $3^{\prime}$ 'direction.

Telomeres also protect chromosomes against abnormal recombination, chromosome fusion (prevents chromosomal aberrations, including translocations, duplications, and deletions), or their degradation as a result of an exonuclease attack (30-32). They are a molecular clock that, after exceeding the limit of divisions, directs the cell to the path of replicative senescence or apoptosis. With each division, the telomeric sequence is shortened by approximately $50-150 \mathrm{bp}$ in human somatic cells in cell culture. The time at which the telomere will be critically shortened may vary. It is a consequence of the heterogeneous distribution of telomeres in different chromosome arms and the specific rate of telomere shortening in individual cell lines (33). Research results indicate that the shortest telomere can be a factor stopping further cell division. Telomere shortening causes telomere conformational changes and loss of T-loop formation, promotes genomic instability and, in combination with other oncogenic changes, can potentially stimulate cancer initiation (34).

Telomeres are also involved in functions such as regulation of gene expression through transcriptional silencing of genes located close to the telomeres, which is called telomere position effect (TPE), or those located at long distances from telomeres, termed TPE over long distances (TPE-OLD) $(35,36)$. 


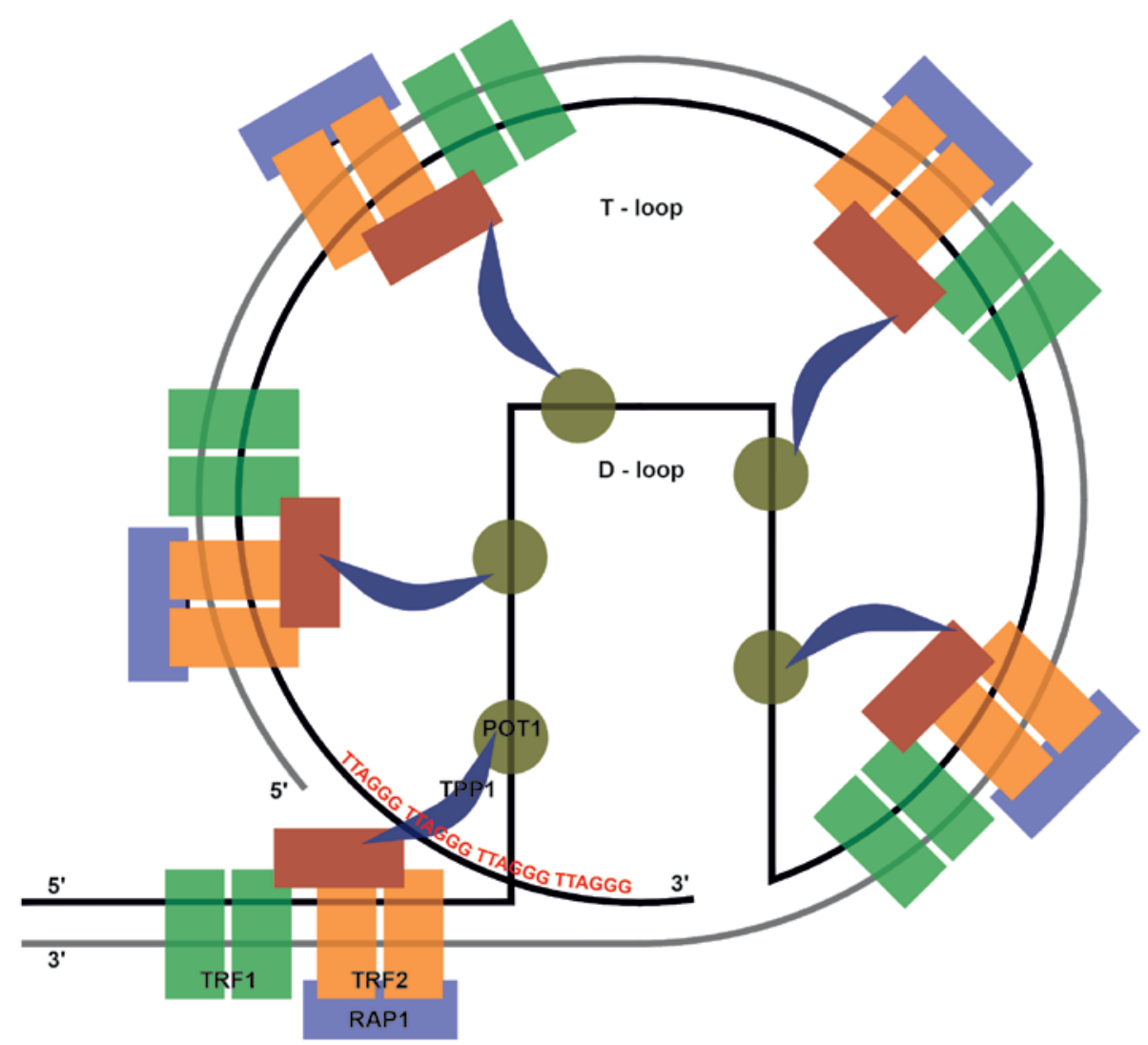

Figure 1. Telomere structure. Telomeric DNA contains tandem repeats of DNA sequence 5'-TTAGGG-3', terminal 3' G-rich overhang and shelterin complex of six subunits: TRF1, TRF2 and POT1 (proteins responsible for recognition of TTAGGG telomeric repeats), and TIN2, TPP1 and RAP1 (complex stabilizing proteins). The telomere structure forms two loops, the T-loop and the D-loop. TRF1, telomere repeat factor-1; TRF2, telomere repeat factor-2; POT1, protection of telomeres-1; TIN2, TRF1 interacting protein-2; RAP1, repressor/activator protein 1; TPP1, TINT1/PTOP/PIP1 protein (POT1-TIN2 organizing protein).

\section{Telomerase}

Most of the telomeric DNA is copied in the replication process. However, telomere deficiency is supplemented by telomerase-catalyzed elongation.

Telomerase, an enzyme made of protein subunits and RNA, comprises a catalytic subunit with reverse transcriptase activity (TERT-telomerase reverse transcriptase), an RNA template (TERC-telomerase RNA component) with a sequence complementary to the sequence of the telomere, and accessory proteins such as discerin, NHP2 ribonucleoprotein, NOP10 ribonucleoprotein, and GAR1 (localization factor). The TERT subunit binds to TERC and the protein complex. Telomerase is recruited to single stranded telomeric DNA through interaction with the telomere-localizing protein TPP1. Additional factors such as the chaperones HSP90 and p23, a WD-repeat-containing protein 79 called TCAB1, as well as the ATPases pontin and reptin are also involved in this process. SRSF11 (TERC-blinding protein) stabilizes the telomerase-telomere complex (37) (Fig. 2).

TERT synthesizes telomeric sequences using TERC as a template. The expression or activity of TERT is regulated at many stages by various factors. Induction of TERT mRNA expression requires binding of the transcription factors c-MYC and SP1 to the E-box (5'-CACGTG-3') and five GC boxes (5'-GGGCGG-3') (38). Other transcription factors such as E2F, AP-1, estrogen response element (ERE) for estrogen receptor $\alpha$ binding, and CCCTC binding factor are involved in the activation of TERT transcription (38). The phosphatidylinositol-3 kinase (PI3K)/AKT pathway enhances TERT activity at the post-translational level via TERT phosphorylation by AKT (39).

Telomerase is activated in germline, hematopoietic, stem and mitotically active, and rapidly regenerating cells. In contrast, telomerase activity is very low or absent in somatic cells, although telomerase activity has been found in normal human blood cells, proliferative basal skin layer, endometrial tissue, intestinal crypt proliferative zone, and hair follicles (40-44).

Telomerase repression and/or shorter telomeres in human cells prevent uncontrolled cell proliferation (2). Lack of telomerase leads to a progressive shortening of telomeres during division because of the nature of DNA polymerase. When the telomere length reaches a critical size, DNA damage occurs and the stage of growth arrest called replicative senescence is activated.

By contrast, cells with strong proliferative potential are characterized by high telomerase activity. These cells include stem cells and embryonic and progenitor cells of the hematopoietic system, skin, and intestinal crypts. Telomerase activity is closely related to the life stages of the body. The enzyme is active during embryonic development.

Cancer cells are characterized by high telomerase activity, which enables cells to divide indefinitely. Telomerase is active in 


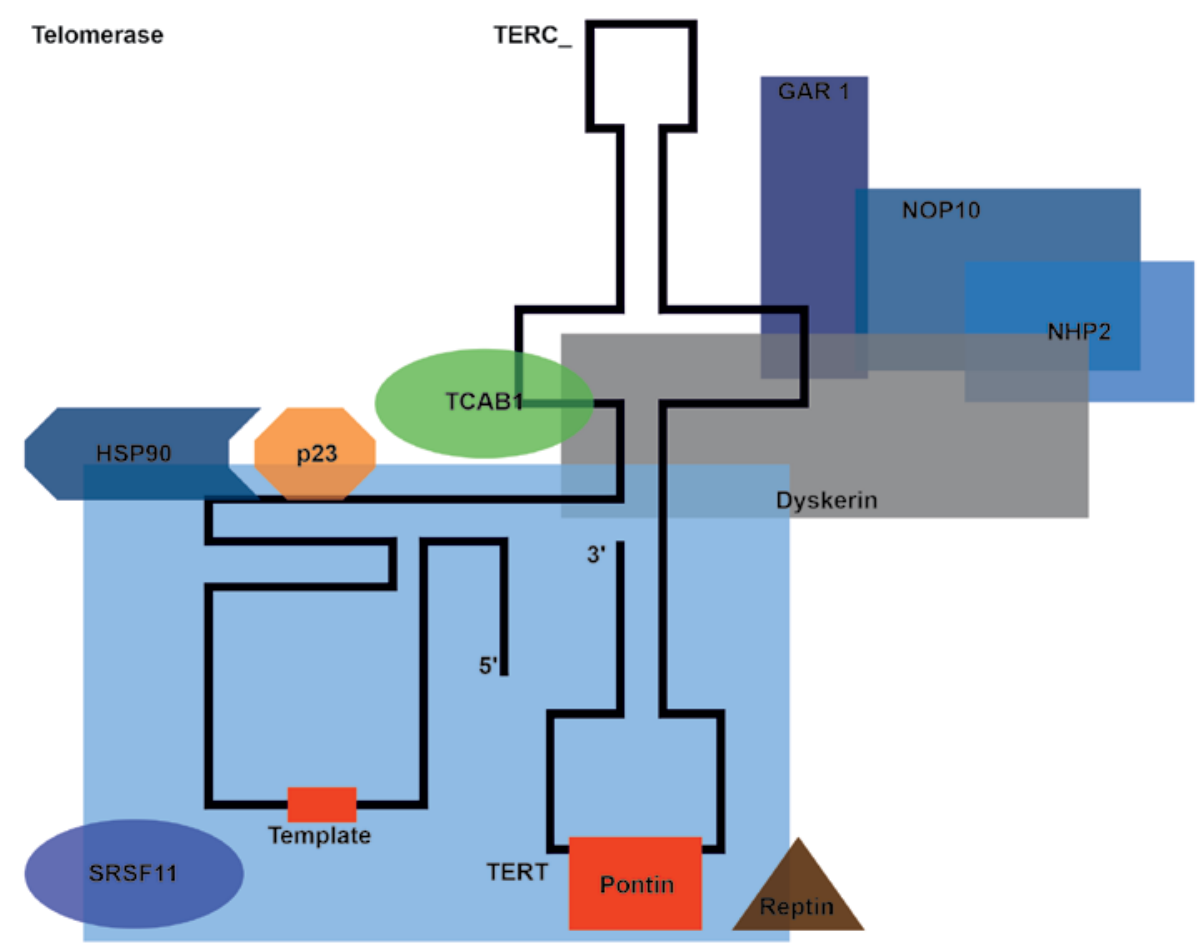

Figure 2. Telomerase structure. Human telomerase is composed of TERC-telomerase RNA component (RNA template), TERT-telomerase reverse transcriptase (catalytic subunit with reverse transcriptase activity) and the accessory proteins. NHP2, non-histone protein 2; NOP10, nucleolar protein 10; GAR1, glycine arginine rich 1; TCAB1, telomerase Cajal body protein 1; HSP90, heat shock protein 90; SRSF11, serine and arginine rich splicing factor 11; TERC, telomerase RNA component; TERT, telomerase reverse transcriptase.

$85-95 \%$ of cancers $(3,4)$. The exception is cancer cells possessing an active Alternative Lengthening of Telomeres (ALT) pathway. ALT, which is the ability of cancer cells to extend telomeres in the absence of telomerase, is based on homologous recombination using telomeric DNA as a matrix (45). ALT activation correlates with the presence of mutations in the genes encoding $\alpha$-thalassemia/mental retardation X-linked chromatin remodeler and death domain associated protein in both tumors and cell lines (46). This process is observed in aggressive, difficult to treat tumors of mesenchymal origin, which account for approximately $5-15 \%$ of all cancers (47).

TERT induction and telomerase activation not only create unlimited cancer cell proliferation potential by stabilizing telomere length (telomere lengthening-dependent), but also cause oncogenic effects independently of the telomere lengthening function. The telomere lengthening-independent functions of TERT, which significantly contribute to cancer initiation or progression, include its effects on mitochondrial and ubiquitin-proteasomal function, DNA damage repair, gene transcription, microRNA (miRNA) expression, RNA-dependent RNA polymerase activity, and epithelial-mesenchymal transition (48-56). These TERT activities physiologically affect the processes that ultimately lead to cell aging; however, they also drive cancer development by conferring survival, proliferation, motherhood, and invasive phenotypes.

Several signalling pathways (mainly c-MYC, NF- $\kappa \mathrm{B}$, $\mathrm{B}-\mathrm{Catenin)}$ are involved in the transcriptional reactivation of TERT in cancer cells. Additionally PI3K/AKT kinase pathway enhances TERT activity at the posttranslational level via phosphorylation. TERT activation occurs as a result of c-MYC binding to the E-box (5'-CACGTG-3') in the TERT promoter region. There is an increase in vascular cell viability and stimulation of c-MYC-dependent oncogenesis potential as a result of induction of transcriptional activity of TERT, stabilization of c-MYC levels on chromatin and c-MYC ubiquitination and proteosomal degradation (57). NF- $\kappa \mathrm{B}$ controls the transcription of TERT via NF- $\kappa \mathrm{B}$ binding sites in the TERT promoter specific for $\mathrm{p} 50$ and $\mathrm{p} 65$.

This pathway induces TERT transcription activities and additionally leads to repression of ROS-dependent activation, modulation of TERT nuclear translocation, recruitment of IL6 and TNF alpha, and upregulation of MMP. Repression of ROS-dependent activation, inflammation and cancer progression occurs as a result of these activities $(54,58,59)$. Wnt/B-Catenin is another pathway involved in the regulation of TERT. Activation of Wnt-depend reporters results in stem cell pluripotency, cell proliferation, and cancer progression (60).

\section{Telomeres as tumor suppressors}

Divisions of human cells that lack telomerase activity lead to shortening of telomeres and disruption of their spatial structure (they lose the ability to form T loops). Telomere shortening is a natural consequence of cell division due to the "end replication problem' and leads to critically shortened telomeres that trigger DDR. The DNA damage detection pathways by chromosomal instability and p53 or p16-RB pathway activation are induced, and the cell enters a stage named replicative senescence. This is thought to be an effective barrier against cancer by blocking proliferation and genetic mutations resulting from DNA replication. Telomeres act as tumor suppressors. If the cells acquire a mutation in the gene encoding p53, which is 
Frequency of TERT promoter mutations in different types of cancer

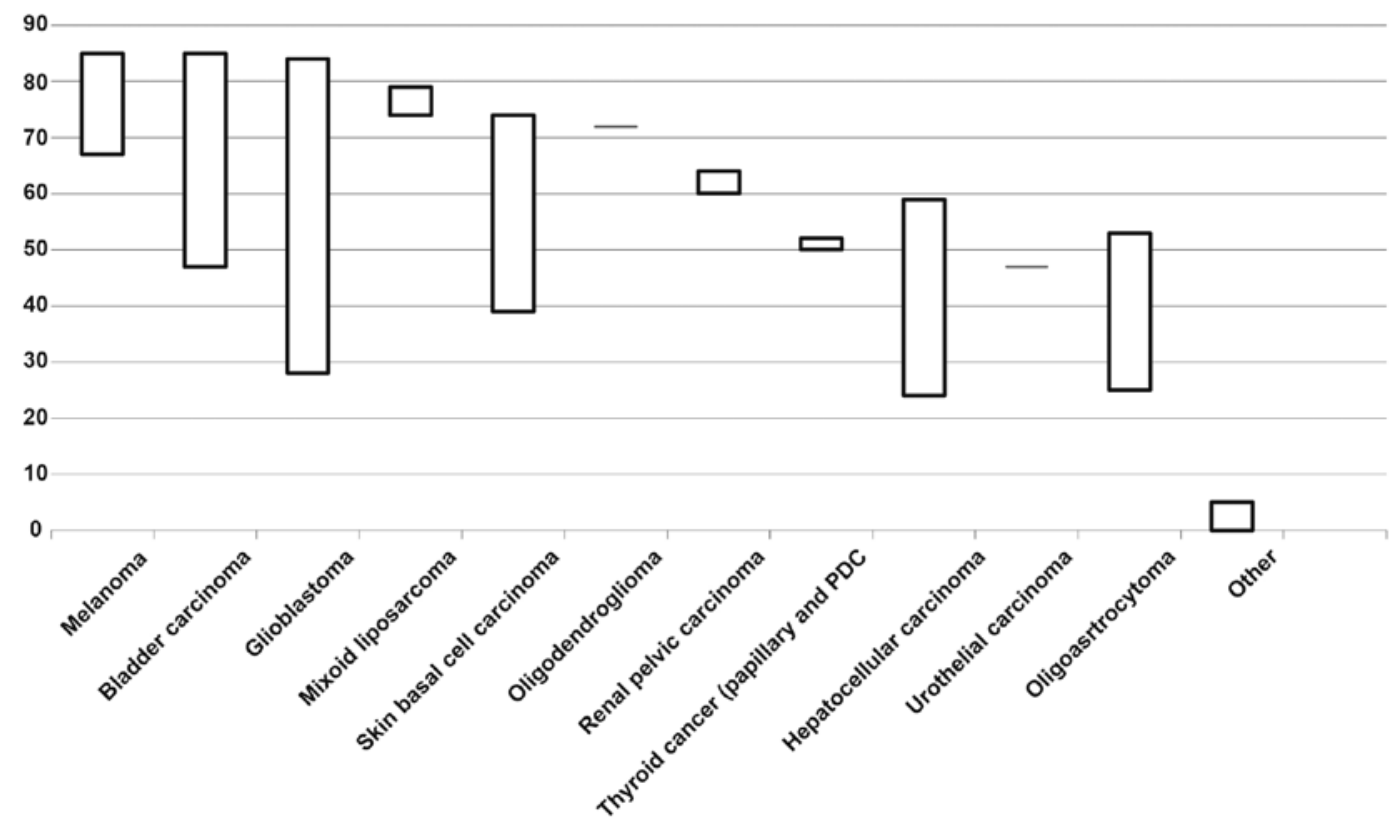

\begin{abstract}
Other : breast cancer, colorectal cancer, medullary thyroid carcinoma, ovarian cancer, espohageal adenocarcinoma, acute myeloid leukemia, chronic lymphoid leukemia, pancreatic cancer, prostate cancer, testicular carcinoma, uterine cervix cancer.

PDC - poorly differentiated carcinoma
\end{abstract}

Figure 3. Frequency of TERT promoter mutations in different types of cancer. Data were obtained from a previous study (37). TERT, telomerase reverse transcriptase; PDC, poorly differentiated carcinoma.

responsible for detecting short telomeres or other checkpoint proteins, they can overcome senescence. The cells will continue to proliferate until telomeres become critically short and then will be directed to apoptosis. As a result of various disorders, some cells $\left(\sim 1 / 10^{7}\right)$ activate telomerase or ALT and acquire the potential for endless proliferation, which makes them immortal (31). Most often this condition is achieved by upregulation or reactivation of telomerase. The rare telomerase negative immortalization pathway termed ALT involves DNA recombination to maintain telomeres.

\section{Mechanisms activating TERT transcription and telomerase in human cancer}

The TERT gene is located on the short arm of chromosome 5. The 433-bp genomic region encompassing $52 \mathrm{CpG}$ sites located immediately upstream of the TERT core promoter region may bind to transcription factors or repressors (61). This region upstream of the TERT promoter is unmethylated in normal human cells, whereas it is methylated in malignant cells. There is also evidence that the unmethylated region upstream of the promoter core sequence is responsible for binding to the repressor (62). Transcriptional regulation of the TERT gene occurs at many levels and is mediated by various positive and negative factors or signaling pathways (4). These factors control the TERT gene and ensure inhibition of TERT activity in most normal cells, as well as its expression at the right time and place in a small number of cell types such as activated lymphocytes or stem cells. This balance may be disturbed in malignant cells. A typical example is the Myc/Max/Mad1 protein. Endogenous expression of the cellular c-MYC oncogene may result in dissociation of the Mad1/Max repressor from the E-box complex, leading to de-repression of the TERT gene and telomerase activation (63).

Epigenetic factors responsible for DNA methylation, histone acetylation, methylation, and phosphorylation are another group of factors modulating TERT transcription. As mentioned, TERT promoter methylation is required for the expression of TERT and activation of telomerase in cancer cells (62).

Some viruses may code for proteins that act as cofactors to stimulate TERT transcription as well. These include Epstein-Barr virus, cytomegalovirus, Kaposi sarcoma-associated herpesvirus, human papillomavirus, hepatitis B virus, hepatitis $\mathrm{C}$ virus, and human T-cell leukemia virus-1 (64).

TERT expression and telomerase activity in tumors are also affected by TERT promoter mutations, which occur mainly at two active points of chromosome 5, C228T and C250T. The incidence of TERT promoter mutations varies from undetectable to over $90 \%$ in various human malignancies. The highest TERT promoter mutation rates (up to 80-90\%) occur in glioblastoma, melanoma, bladder urothelial carcinoma, and brain lower-grade glioma. An intermediate mutation frequency range is observed in liver hepatocellular carcinoma and thyroid carcinoma. The lowest level of mutation frequency $(<10 \%)$ is detected in kidney, lung, prostate, and gastrointestinal cancers and in leukemia (65). The mutation frequency of the TERT promoter varies depending on the type of cancer (Fig. 3) (22,37,66-72). The C228T mutation is more common than the $\mathrm{C} 250 \mathrm{~T}$ mutation. These mutations form 
the binding site for E-twenty six (ETS) transcription factors. In addition, GABPA and GABPB1 (ETS family members) binding proteins form heterotetramers that bind to the de novo ETS site and activate TERT transcription (73).

The presence of the TERT promoter mutation is negatively correlated with telomere length and is associated with older patients (4). Telomere damage causing their dysfunction and genomic instability, which are often observed in old age, may be due to short telomeres (3).

Some viruses may code for proteins that act as cofactors to stimulate TERT transcription as well. These include Epstein-Barr virus, cytomegalovirus, Kaposi sarcoma-associated herpesvirus, human papillomavirus, hepatitis B virus, hepatitis $\mathrm{C}$ virus, and human T-cell leukemia virus-1 (64). Targeted activation is one of the key mechanisms of carcinogenesis through a virus. For example, HPV E6 is a viral oncoprotein that forms a complex with E6AP and c-Myc. This complex binds to the E-box in the TERT core promoter and induces TERT activation. Another well-studied cofactor is the CMV early protein 72 , which by interacting with Sp1 activates TERT transcription (64). Recent studies indicate that rearrangements and insertions of the oncogenic viral genome at the TERT locus are new mechanisms underlying increased expression of TERT by hijacking enhancers (74). Recent evidence suggests that viral DNA integration at the TERT locus may trigger an additional TERT regulatory mechanism; an exogenous viral enhancer was found to drive endogenous TERT transcription (74). Enhancers regulate gene transcription by interacting with gene promoters, regardless of their position relative to the place of transcription initiation. These factors make DNA more accessible to the transcription machine. Functionally, rearrangements and onco-viral DNA cause active enhancers to affect the TERT gene and increase TERT expression (75).

High-throughputnew generation sequencing of humancancers has also provided genomic information on TERT amplification and the important role of this genomic aberration in telomerase activation during cancer development. Barthel et al (65) analyzed more than 6,000 cancer patients and found that $4 \%$ of the studied tumors show TERT gene amplification with high frequency in ovarian cancer, adrenal cortical cancer, esophageal cancer, and lung cancer. In addition, the highest telomerase activity was found in tumors with TERT amplification.

\section{TERT promoter mutations-cancer-specific biomarkers in diagnostics/screening}

Telomerase repression in combination with shorter telomeres are protective mechanisms against cancer. Human somatic cells achieve malignant transformation through TERT gene de-repression/telomerase reactivation in most cases. The assessment of cancer-specific expression of TERT or telomerase activation is the experimental field for the potential clinical application of cancer tests (3).

However, there have been difficulties in using reliable tests to evaluate TERT or telomerase activity for diagnostic or screening purposes.

On the one hand, false positive results of TERT expression found in lymphocytes associated with inflammation or infiltrating tumors. On the other hand, telomerase and mRNA TERT are temperature sensitive, so managing them is difficult and at the same time requires high quality tissue samples. An additional problem is the specificity of the available TERT antibodies for immune-histochemical staining or immunoblotting (4).

Researchers have mainly focused on assessing TERT promoter mutations in various cancers. The presence of the TERT promoter mutation in human malignancies and its absence from normal cells creates new cancer-specific markers. DNA stability enables the routine use of mutation analysis. Detection of the mutant TERT promoter in plasma, urine, and cerebral spinal fluid (CSF) serves as a useful biomarker in hepatocellular carcinoma, bladder cancer, and glioma, respectively (76-78). In addition, the detection of methylated $\mathrm{CpG}$ in the TERT promoter region in the feces may be useful for the diagnosis of gastrointestinal cancer (79). Evaluation of the methylated TERT promoter in CSF may be a useful non-invasive diagnostics tool for predicting metastases to the meninges (80). In addition, analysis of circulating oncogenic miRNAs targeting TERT expression can be a useful diagnostic tool. miRNA assessment in blood can be a valuable biomarker in cancer (81).

\section{TERT promoter mutations-prognostic factors in cancer/sign of aggressiveness}

Abnormal expression of TERT and hypermethylation of the TERT promoter serve as prognostic factors in many types of human cancer. The presence of the TERT promoter mutation is an unfavorable prognostic factor (metastasis/survival) in melanoma and glioma $(82,83)$. In thyroid cancers, mutation of the TERT promoter is associated with poor biological characteristics and a low rate of survival, and includes differentiated thyroid cancers with aggressive clinical behavior, poorly differentiated thyroid cancers (PDTC), and anaplastic thyroid cancers (ATC) $(84,85)$. The association of TERT promoter hypermethylation with poor results and cancer prognosis in brain tumors and adrenal cortical cancer has also been reported $(86,87)$.

The relationship between the coexistence of TERT promoter and $B R A F$ V600E mutations and a poor disease course has been reported in thyroid cancer and melanoma $(88,89)$. The synergy in the coexistence of TERT promoter and $B R A F$ $V 600 E$ mutations is most likely caused by the activation of the mitogen-activated protein kinase (MAPK) and/or PI3-Akt pathways, which upregulate ETS transcription factors and trigger the expression of TERT. Recently, Liu et al (90) demonstrated that BRAF V600E enhances the activation of the MAPK pathway, leading to the FOS-mediated expression of GABPB, which binds to TERT mutated promoters and induces TERT expression. In addition, a significant relationship was observed between TERT promoter mutations and RAS mutations that often occur in PDTC and ATC (85).

Liu et al (91) reported that KRAS mutations increase TERT mRNA expression by activating the RAS/MEK pathway, which contributes to the aggressive phenotype of non-small cell lung cancer (NSCLC).

\section{Telomere shortening in cancer and its potential advantage}

Although tumors with telomerase activation acquire the ability to extend the telomere, telomere length is shorter in prostate 


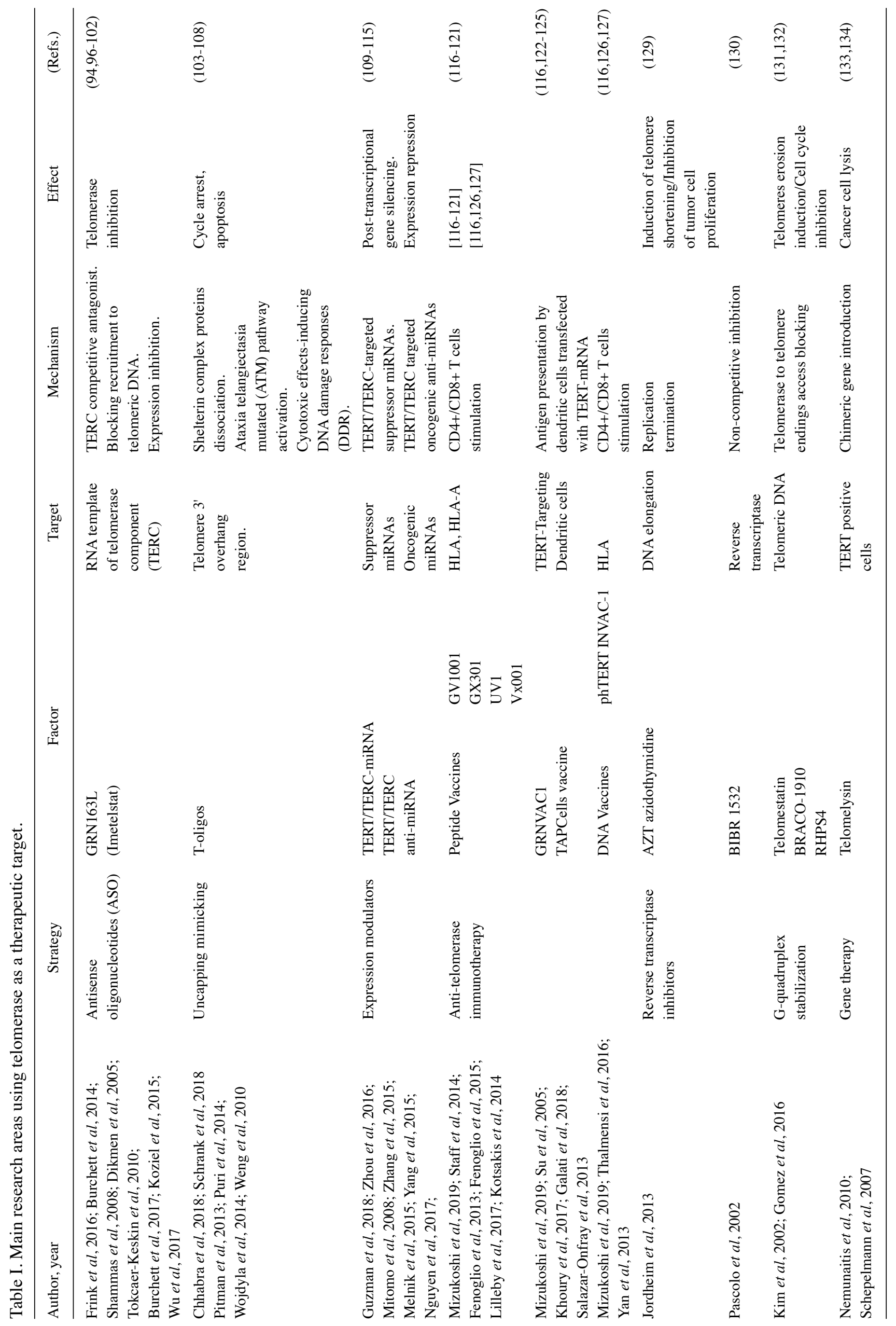


cancer than in normal tissues (92). Recent genome-wide analyses have shown that $70 \%$ of the cohorts have shorter telomeres than normal samples (65). Cancer cells with short telomeres show upregulation of interferon-stimulated genes, which is likely to contribute to the malignancy of the tumor. In addition, truncated telomeres facilitate cancer evolution, resulting in moderate chromosome instability (93). Theoretically, genetic or pharmacological inhibition of telomerase activity in TERT-positive cancer cells should have an antitumor effect. In addition, we would expect the anticancer effect of telomerase inhibition to appear earlier in cancer cells with shorter telomeres. In fact, a short telomeric length may be a predictive biomarker of the efficacy of telomerase inhibitors (94). The Imetelstat telomerase inhibitor increases the median progression-free survival and overall survival of NSCLC patients with short telomeres (95).

\section{Telomeres as a possible therapeutic target}

Telomerase is expressed in most types of cancer and in cancer stem cells and is the focus of cancer treatments. Normal human cells have lower telomerase activity and usually have longer telomeres than cancer cells. The main point of anti-telomerase therapy is the selective destruction of cancer cells while minimizing the effect on normal cells (due to the presence of longer telomeres compared to cancer cells). Many therapeutic approaches have been adopted to achieve this goal (Table I).

Oligonucleotides. Therapies based on telomerase-targeted oligonucleotides include GRN163L (Imetelstat). This 13-mer oligonucleotide sequence is a competitive antagonist that binds to the TERC template region. It blocks its recruitment to telomeric DNA and leads to complete inhibition of telomerase activity. Imetelstat has been studied in glioblastoma, bladder, breast, liver, prostate, and pancreatic cancer and shows promising antitumor activity, although it is too toxic as a stand-alone therapy (94). GRN163L treated pancreatic cancer and myeloma cells showed growth similar to untreated cells for the first 3-8 and 3-5 weeks, respectively, but later began to undergo progressive aging and apoptosis $(96,97)$. Significant reduction of rapid cellular attachment and reduction of metastatic lesions has been demonstrated for lung cancer cells expressing A549-luciferase treated with GRN163L (98). Despite promising anti-cancer effects, the use of GRN163L in clinical settings is limited due to its hematological toxicity. Neutropenia and thrombocytopenia require frequent drug holidays, limiting the effectiveness of GRN163L as a therapeutic agent (95). Another problem associated with GRN163L is its harmful effect on mesenchymal stem cells. A change in mesenchymal stem cell morphology, loss of adhesion, and G1 phase arrest of the cell cycle have been demonstrated (99). Although the use of GRN163L alone is currently ineffective, it has been shown to have promising effects in combination with other molecularly targeted drugs or in the sensitization of cancer cells to radiation therapy (100-102).

T-oligos homologous to the 3'-telomeric overhang are also promising oligonucleotides that have demonstrated anticancer activity. They dissociate shelterin complex proteins, activate the ataxia telangiectasia mutated pathway, and exert cytotoxic effects by inducing the DDR (103). However, rapid degradation by nucleases and an incomplete explanation of its mechanism of action remain obstacles to the introduction of T-oligos into clinical trials (104). They dissociate shelterin complex proteins, activate the ataxia telangiectasia mutated pathway (ATM) and its downstream effectors p53, pRb, E2F1, cdk2, and p95/NBS1 and exert cytotoxic effects by inducing the DDR. Two models explain the mechanism of anti-cancer action by T-oligo. The first assumes that T-oligo accumulating in the nucleus are detected by homology to the telomere as damaged DNA and DDR activation occurs. The second model assumes the action of T-oligos by dissociating shelter proteins, thereby exposing the telomere overhang and inducing responses to DNA damage (104). T-oligo anti-tumor activity has been demonstrated in vitro in cancers such as melanoma, lymphoma, lung, breast, prostate, pancreas, colorectal and ovarian cancer (104-106). However, rapid degradation by nucleases and an incomplete explanation of its mechanism of action remain obstacles to the introduction of T-oligos into clinical trials (104). Therefore, the efforts of researchers are directed to the search for methods of inhibition by nucleases. In addition, the use of T-oligo in combined therapies has shown promising results. Additive inhibition has been demonstrated in combination with an EGFR (gefitinib) inhibitor in colorectal cancer (107). T-oligo also increases the sensitivity of breast cancer cells to radiation therapy (108).

miRNAs are an endogenous group of oligonucleotides that regulate gene expression at the post-transcriptional level, effectively silencing genes by interacting with the RNA-Induced Silencing Complex. Carcinogenic miRNAs may exist as oncogenic miRNAs or suppressor miRNAs that promote or inhibit the development of cancer, respectively. Several miRNAs (miR-128, miR-138, miR-1182, miR-342, miR-491, and miR-541) negatively regulate the expression of the TERT gene, thereby acting as tumor suppressor miRNAs (109). Overexpression of miR-138 has been shown to inhibit cell proliferation, invasion and induce apoptosis in cervical cancer (110). In contrast, a decrease in the level of miR-138 is observed in anaplastic thyroid cancer (111). Another study found that miR-1182 reduced the proliferation and migration of gastric cancer cells (112). In contrast, miR-128 can act as either oncogenic or suppressor miRNA, depending on interaction with various targets (109). TERC-targeted miRNAs may act as telomerase inhibitors and are being tested in clinical applications. Unfortunately, inhibition of telomerase induces an anti-tumor effect when they lead to a critical shortening of telomere, usually after weeks of treatment. In addition, the effect of miRNA reducing telomerase activity in stem cells requires further study. Oncogenic miRNAs such as miR-21 that cause tumor transformation by regulating TERT expression have been identified. The participation of miR-21 in melanoma, colorectal cancer or glioma has been described $(113,114)$. The use of anti-miRNAs that are antisense to target miRNAs and block their action has been reported. miRNA inhibition in cancer treatment remains in the preclinical stages (115).

Anti-telomerase immunotherapy. Telomerase-based vaccines sensitize immune cells to cancer cells expressing TERT peptides as surface antigens via the human leukocyte antigen (HLA) class I and class II pathways. The expansion of $\mathrm{CD}^{+}$and $\mathrm{CD}^{+}$cytotoxic $\mathrm{T}$ lymphocytes (CTL) specific for 
oncogenic telomerase causes T cells to kill telomerase-positive tumor cells (116).

TERT-targeted peptide vaccines. GV1001 is the most advanced of all TERT vaccines. It induces specific $\mathrm{T}$ cell responses in pancreatic cancer, NSCLC, and melanoma (117). It is a MHC class II restricted peptide vaccine that elicits strong $\mathrm{CD}^{+}{ }^{+}$and $\mathrm{CD}^{+} \mathrm{T}$ cell responses and cytotoxic $\mathrm{T}$ lymphocytes (CTL) activation. Clinical studies have shown that it induces $\mathrm{T}$ cell responses in $50-80 \%$ of patients with advanced pancreatic cancer and lung cancer without clinical toxicity. The vaccine did not affect bone marrow cells (116). GX301, a vaccine consisting of four peptides derived from TERT, is more effective than single-peptide vaccines; it has been tested in patients with prostate cancer and kidney cancer (118). The results of these studies indicate that multi-peptide vaccines are more effective because they enhance the immune response in more responders than single-peptide vaccines (119). Immune responses to UV1 or $\mathrm{Vx}-001$ vaccines were demonstrated in prostate cancer and NSCLC, respectively $(120,121)$. The first of these induced an immune response in $85.7 \%$ of patients and reduced prostate-specific antigen (PSA) levels in $64 \%$ of patients with metastatic prostate cancer (120). Similarly, the second vaccine elicited a strong TERT-specific immune response in NSCLC and had a good tolerance profile (121).

Immunotherapy using TERT-targeting dendritic cells (DC). DCs are the strongest antigen presenting cells and play an important role in inducing immunity. GRNVAC1 is a DC-based cancer vaccine that elicits a polyclonal immune response. Previous clinical studies have shown that GRNVAC1 is effective, safe and well tolerated in patients with prostate cancer and acute myeloid leukemia $(122,123)$.

Another DC-based approach is to produce therapeutic dendritic-like cells called tumor antigen presenting cells (TAPCells) (124). This vaccine has been evaluated in patients with advanced stage melanoma and castration-resistant prostate cancer. It increased the survival of patients with melanoma and extended the doubling time of PSA (125).

DNA vaccines. The genome encoding the TERT peptide can be created using recombinant DNA technology. Plasmids containing these genomes can be delivered to antigen presenting cells, which improves the efficiency of epitope presentation in T lymphocytes. phTERT is a DNA-based vaccine that codes for TERT, whereas INVAC-1 is a plasmid that codes for the inactive form of TERT (126). The phTERT and INVAC-1 vaccines inhibited tumor proliferation and prolonged survival in the HPV-related and melanoma-related tumor model, respectively $(126,127)$.

Gene-modified T-cell therapy. This is another promising method based on the use of $\mathrm{T}$ cells genetically modified to produce the T-cell receptor, which recognizes tumor antigens and their epitopes (128).

Nucleosides. Azidothymidine (AZT) was the first reported telomerase inhibitor. AZT inhibits telomerase irreversibly. AZT has a synergistic effect with paclitaxel and significantly enhances its effect. It is used to treat many human cancers associated with viruses, whereas in non-viral tumors, it causes some degree of regression (129). Acyclic nucleoside analogs such us acyclovir, ganciclovir, and penciclovir have been identified as inhibitors or antagonists of telomerase.

Small molecule inhibitors. The BIBR1532 acid is a non-nucleotide small molecule compound that selectively inhibits telomerase activity by non-competitive binding to the active site of TERT (130). Although preclinical studies on breast and prostate cancer cell lines have shown good results, no further inclusion in clinical trials has been reported.

Stabilization of $G$ quadruplexes. Stabilization of G-quadruplexes prevents TERC from recognizing the unfolded single-stranded telomere overhang, thereby inhibiting telomerase activity. Compounds that stabilize G-quadruplexes include telomestatin, RHPS4, and BRACO19 (131). Other compounds that stabilize G-quadruplexes and inhibit telomerase are being investigated. Daunomycin, distamycin A, ascididemin and meridine, berberine, cryptolepine derivatives, and cationic porphyrins are being studied as possible telomerase inhibitors because of their ability to bind and stabilize G-quadruplexes (132).

Gene therapy. Imetelstat (GRN163L) is one of the best known gene therapy molecules, it was previously described in paragraph 10 (133). Other strategies include the introduction of a chimeric gene, namely, the coding sequence of a proapoptotic protein under the control of the TERT gene promoter. Telomelysine is an attenuated adenovirus-5 vector that induces lysis of cancer cells overexpressing TERT (133). Another approach involves the use of viral vectors that have been genetically modified to encode a cytotoxic prodrug activating enzyme (134).

Targeting telomeres and telomerase-associated proteins. Therapeutic approaches based on targeting telomerase-related proteins have been investigated. One of these strategies is targeting tankyrase (the enzyme responsible for the correct separation of chromosomes) with PARP inhibitors. Also interesting is the inhibition of the chaperone HSP90 (required for maturation and activation of telomerase) by Geldanamycin (135). Molecules against TRF1, TRF2, and TIN2 or POT1 have also been analyzed (136).

Telomerase inhibitors derived from natural products and microbial sources. Natural products capable of telomerase inhibition as potential chemotherapeutic agents for cancer treatment have been identified. Natural products from plants with activity against telomerase include polyphenols (curcumin, quercetin, resveratrol, and tannic acid), alkaloids (boldine and berberine), terpenoids (pristimerin and oleanane), and xanthones (gambogic acid and gambogenic acid) (137). Oleic acid is a fatty acid that occurs in various animal and vegetable oils, is classified as omega- 9 monounsaturated fatty acid, and has been identified as a human telomerase inhibitor (138). Actinomycetes spp. are microorganisms containing benzofuran and benzodipyrane rings that act as telomerase inhibitors. Rubromycins isolated from Streptomyces collinus 
that have telomerase inhibitory activity have recently been studied (138).

Telomerase and oxidative stress. Studies have reported telomerase damage induced by reactive oxygen species (ROS). Antioxidant enzymes such as peroxiredoxin 1 (PRDX1) and the nudix phosphohydrolase superfamily enzyme (MTH1) protect telomeres against oxidative stress. Cancer cells are more vulnerable to ROS than noncancer cells. Combination therapy with ROS-inducing chemotherapeutic agents and inhibitors of proteins that protect telomeres from ROS (such as PRDX1 and MTH1) could selectively target telomere maintenance in cancer cells (139).

\section{Conclusions}

Understanding the structure of telomeres and the mechanism of action of telomerase provides hope for the identification of new forms of cancer treatment. The high specificity of telomerase and the potential for inhibiting its activity at various stages underlie its value as a target for cancer therapy. Many in vitro studies of telomerase inhibition have been conducted to date, and clinical trials are in the early stages. The combination of telomerase inhibitory agents with cytostatic drugs or radiation therapy increases the effectiveness of existing therapies. The results so far point to the huge possibilities of using telomerase for the development of new targeted therapies and for improving the efficacy of current anticancer drugs. Further studies are required to develop TERT-based cancer therapeutic interventions.

\section{Acknowledgements}

Not applicable.

\section{Funding}

The project was financed under the program of the Minister of Science and Higher Education called 'Regional Initiative of Excellence' (project no. 024/RID/2018/19).

\section{Availability of data and materials}

Not applicable.

\section{Authors' contributions}

TT and AlK developed the concept. TT and AlK developed the methodology. TT, ArK, SG and AlK were involved in validation. TT, ArK, SG and AlK prepared the original draft. TT, ArK, SG and AlK reviewed and edited the manuscript. TT, ArK and AlK were responsible for visualization. TT and AlK supervised the study. $\mathrm{TT}$ and AlK were involved in project administration. All authors read and approved the final manuscript.

\section{Ethics approval and consent to participate}

Not applicable.

\section{Patient consent for publication}

Not applicable.

\section{Competing interests}

The authors declare that they have no competing interests.

\section{References}

1. WHO: Cancer, https://www.who.int/news-room/fact-sheets/ detail/cancer

2. Seluanov A, Gladyshev VN, Vijg J and Gorbunova V: Mechanisms of cancer resistance in long-lived mammals. Nat Rev Cancer 18: 433-441, 2018.

3. Shay JW and Wright WE: Telomeres and telomerase: Three decades of progress. Nat Rev Genet 20: 299-309, 2019.

4. Liu T, Yuan X and Xu D: Cancer-specific telomerase reverse transcriptase (TERT) promoter mutations: Biological and clinical implications. Genes (Basel) 7: pii: E38, 2016.

5. Yuan X, Larsson $C$ and Xu D: Mechanisms underlying the activation of TERT transcription and telomerase activity in human cancer: Old actors and new players. Oncogene 38: 6172-6183, 2019.

6. Dilley RL and Greenberg RA: ALTernative telomere maintenance and cancer. Trends Cancer 1: 145-156, 2015.

7. Hayflick L: The limited in vitro lifetime of human diploid cell strains. Exp Cell Res 37: 614-636, 1965.

8. Olovnikov AM: A theory of marginotomy. The incomplete copying of template margin in enzymic synthesis of polynucleotides and biological significance of the phenomenon. $\mathrm{J}$ Theor Biol 41: 181-190, 1973 .

9. Szostak JW and Blackburn EH: Cloning yeast telomeres on linear plasmid vectors. Cell 29: 245-255, 1982.

10. Blackburn EH: Structure and function of telomeres. Nature 350: 569-573, 1991.

11. Greider CW: Telomerase is processive. Mol Cell Biol 11: 4572-4580, 1991.

12. Moyzis RK, Buckingham JM, Cram LS, Dani M, Deaven LL, Jones MD, Meyne J, Ratliff RL and Wu JR: A highly conserved repetitive DNA sequence, (TTAGGG)n, present at the telomeres of human chromosomes. Proc Natl Acad Sci USA 85: 6622-6626, 1988.

13. Makarov VL, Hirose Y and Langmore JP: Long G tails at both ends of human chromosomes suggest a $\mathrm{C}$ strand degradation mechanism for telomere shortening. Cell 88: 657-666, 1997.

14. Wellinger RJ and Sen D: The DNA structures at the ends of eukaryotic chromosomes. Eur J Cancer 33: 735-749, 1997.

15. Blackburn EH: Switching and signaling at the telomere. Cell 106: 661-673, 2001.

16. Greider CW and Blackburn EH: A telomeric sequence in the RNA of Tetrahymena telomerase required for telomere repeat synthesis. Nature 337: 331-337, 1989.

17. Lendvay TS, Morris DK, Sah J, Balasubramanian B and Lundblad V: Senescence mutants of Saccharomyces cerevisiae with a defect in telomere replication identify three additional EST genes. Genetics 144: 1399-1412, 1996.

18. Lingner J and Cech TR: Purification of telomerase from Euplotes aediculatus: Requirement of a primer 3' overhang. Proc Natl Acad Sci USA 93: 10712-10717, 1996.

19. Liu L, Lai S, Andrews LG and Tollefsbol TO: Genetic and epigenetic modulation of telomerase activity in development and disease. Gene 340: 1-10, 2004.

20. Kim NW, Piatyszek MA, Prowse KR, Harley CB, West MD, Ho PL, Coviello GM, Wright WE, Weinrich SL and Shay JW: Specific association of human telomerase activity with immortal cells and cancer. Science 266: 2011-2015, 1994.

21. Shay JW and Bacchetti S: A survey of telomerase activity in human cancer. Eur J Cancer 33: 787-791, 1997.

22. Horn S, Figl A, Rachakonda PS, Fischer C, Sucker A, Gast A, Kadel S, Moll I, Nagore E, Hemminki K, et al: TERT promoter mutations in familial and sporadic melanoma. Science 339: 959-961, 2013.

23. Huang FW, Hodis E, Xu MJ, Kryukov GV, Chin L and Garraway LA: Highly recurrent TERT promoter mutations in human melanoma. Science 339: 957-959, 2013. 
24. Zimmermann M, Kibe T, Kabir S and de Lange T: TRF1 negotiates TTAGGG repeat-associated replication problems by recruiting the BLM helicase and the TPP1/POT1 repressor of ATR signaling. Genes Dev 28: 2477-2491, 2014.

25. Arnoult $\mathrm{N}$ and Karlseder J: Complex interactions between the DNA-damage response and mammalian telomeres. Nat Struct Mol Biol 22: 859-866, 2015.

26. Denchi EL and de Lange T: Protection of telomeres through independent control of ATM and ATR by TRF2 and POT1. Nature 448: 1068-1071, 2007.

27. Janoušková E, Nečasová I, Pavloušková J, Zimmermann M Hluchý M, Marini V, Nováková M and Hofr C: Human Rap1 modulates TRF2 attraction to telomeric DNA. Nucleic Acids Res 43: 2691-2700, 2015.

28. Frescas D and de Lange T: TRF2-tethered TIN2 can mediate telomere protection by TPP1/POT1. Mol Cell Biol 34: 1349-1362, 2014.

29. Stewart JA, Chaiken MF, Wang F and Price CM: Maintaining the end: Roles of telomere proteins in end-protection, telomere replication and length regulation. Mutat Res 730: 12-19, 2012.

30. Martínez P and Blasco MA: Telomeric and extra-telomeric roles for telomerase and the telomere-binding proteins. Nat Rev Cancer 11: 161-176, 2011.

31. Kowalska A and Kowalik A: Telomeres and telomerase in oncogenesis. Contemp Oncol (Pozn) 10: 485-496, 2006.

32. Shore D and Bianchi A: Telomere length regulation: Coupling DNA end processing to feedback regulation of telomerase. EMBO J 28: 2309-2322, 2009.

33. Bourgeron T, Xu Z, Doumic M and Teixeira MT: The asymmetry of telomere replication contributes to replicative senescence heterogeneity. Sci Rep 5: 15326, 2015.

34. Hemann MT, Strong MA, Hao LY and Greider CW: The shortest telomere, not average telomere length, is critical for cell viability and chromosome stability. Cell 107: 67-77, 2001.

35. Pedram M, Sprung CN, Gao Q, Lo AWI, Reynolds GE and Murnane JP: Telomere position effect and silencing of transgenes near telomeres in the mouse. Mol Cell Biol 26: 1865-1878, 2006

36. Robin JD, Ludlow AT, Batten K, Magdinier F, Stadler G, Wagner KR, Shay JW and Wright WE: Telomere position effect: Regulation of gene expression with progressive telomere shortening over long distances. Genes Dev 28: 2464-2476, 2014.

37. Jafri MA, Ansari SA, Alqahtani MH and Shay JW: Roles of telomeres and telomerase in cancer, and advances in telomerase-targeted therapies. Genome Med 8: 69, 2016

38. Kyo S, Takakura M, Fujiwara T and Inoue M: Understanding and exploiting hTERT promoter regulation for diagnosis and treatment of human cancers. Cancer Sci 99: 1528-1538, 2008.

39. Kang SS, Kwon T, Kwon DY and Do SI: Akt protein kinase enhances human telomerase activity through phosphorylation of telomerase reverse transcriptase subunit. J Biol Chem 274 13085-13090, 1999.

40. Broccoli D, Young JW and de Lange T: Telomerase activity in normal and malignant hematopoietic cells. Proc Natl Acad Sci USA 92: 9082-9086, 1995

41. Härle-Bachor C and Boukamp P: Telomerase activity in the regenerative basal layer of the epidermis inhuman skin and in immortal and carcinoma-derived skin keratinocytes. Proc Natl Acad Sci USA 93: 6476-6481, 1996.

42. Kyo S, Takakura M, Kohama T and Inoue M: Telomerase activity in human endometrium. Cancer Res 57: 610-614, 1997.

43. Hiyama K, Hirai Y, Kyoizumi S, Akiyama M, Hiyama E, Piatyszek MA, Shay JW, Ishioka S and Yamakido M: Activation of telomerase in human lymphocytes and hematopoietic progenitor cells. J Immunol 155: 3711-3715, 1995.

44. Ramirez RD, Wright WE, Shay JW and Taylor RS: Telomerase activity concentrates in the mitotically active segments of human hair follicles. J Invest Dermatol 108: 113-117, 1997.

45. Cesare AJ and Reddel RR: Alternative lengthening of telomeres: Models, mechanisms and implications. Nat Rev Genet 11: 319-330, 2010

46. Heaphy CM, de Wilde RF, Jiao Y, Klein AP, Edil BH, Shi C, Bettegowda C, Rodriguez FJ, Eberhart CG, Hebbar S, et al: Altered telomeres in tumors with ATRX and DAXX mutations. Science 333: 425, 2011

47. Henson JD, Hannay JA, McCarthy SW, Royds JA, Yeager TR Robinson RA, Wharton SB, Jellinek DA, Arbuckle SM, Yoo J, et al: A robust assay for alternative lengthening of telomeres in tumors shows the significance of alternative lengthening of telomeres in sarcomas and astrocytomas. Clin Cancer Res 11: $217-225,2005$
48. Im E, Yoon JB, Lee HW and Chung KC: Human telomerase reverse transcriptase (hTERT) positively regulates $26 \mathrm{~s}$ proteasome activity. J Cell Physiol 232: 2083-2093, 2017.

49. Hu C, Ni Z, Li BS, Yong X, Yang X, Zhang JW, Zhang D, Qin Y, Jie MM, Dong H, et al: hTERT promotes the invasion of gastric cancer cells by enhancing FOXO3a ubiquitination and subsequent ITGB1 upregulation. Gut 66: 31-42, 2017.

50. Saretzki G: Extra-telomeric functions of human telomerase: Cancer, mitochondria and oxidative stress. Curr Pharm Des 20 6386-6403, 2014

51. Masutomi K, Possemato R, Wong JM, Currier JL, Tothova Z, Manola JB, Ganesan S, Lansdorp PM, Collins K and Hahn WC: The telomerase reverse transcriptase regulates chromatin state and DNA damage responses. Proc Natl Acad Sci USA 102: 8222-8227, 2005.

52. Liu Z, Li Q, Li K, Chen L, Li W, Hou M, Liu T, Yang J, Lindvall C, Björkholm M, et al: Telomerase reverse transcriptase promotes epithelial-mesenchymal transition and stem cell-like traits in cancer cells. Oncogene 32: 4203-4213, 2013.

53. Zhang K, Guo Y, Wang X, Zhao H, Ji Z, Cheng C, Li L, Fang Y, $\mathrm{Xu}$ D, Zhu HH and Gao WQ: WNT/ $\beta$-catenin directs self-renewal symmetric cell division of hTERThigh prostate cancer stem cells. Cancer Res 77: 2534-2547, 2017.

54. Ding D, Xi P, Zhou J, Wang M and Cong YS: Human telomerase reverse transcriptase regulates MMP expression independently of telomerase activity via NF- $\mathrm{BB}$-dependent transcription. FASEB J 27: 4375-4383, 2013.

55. Lassmann T, Maida Y, Tomaru Y, Yasukawa M, Ando Y, Kojima M, Kasim V, Simon C, Daub CO, Carninci P, et al: Telomerase reverse transcriptase regulates microRNAs. Int J Mol Sci 16: 1192-1208, 2015.

56. Drevytska TI, Nagibin VS, Gurianova VL, Kedlyan VR, Moibenko AA and Dosenko VE: Silencing of TERT decreases levels of miR-1, miR-21, miR-29a and miR-208a in cardiomyocytes. Cell Biochem Funct 32: 565-570, 2014

57. Koh CM, Khattar E, Leow SC, Liu CY, Muller J, Ang WX, Li Y, Franzoso G, Li S, Guccione E and Tergaonkar V: Telomerase regulates MYC-driven oncogenesis independent of its reverse transcriptase activity. J Clin Invest 125: 2109-2122, 2015.

58. Mattiussi M, Tilman G, Lenglez S and Decottignies A: Human telomerase represses ROS-dependent cellular responses to tumor necrosis factor- $\alpha$ without affecting NF- $\kappa$ B activation. Cell Signal 24: 708-717, 2012.

59. Ghosh A, Saginc G, Leow SC, Khattar E, Shin EM, Yan TD, Wong M, Zhang Z, Li G, Sung WK, et al: Telomerase directly regulates $\mathrm{NF}-\kappa \mathrm{B}$-dependent transcription. Nat Cell Biol 14: 1270-1281, 2012.

60. Zhang Y, Toh L, Lau P and Wang X: Human telomerase reverse transcriptase (hTERT) is a novel target of the Wnt/ $\beta$-catenin pathway in human cancer. J Biol Chem 287: 32494-32511, 2012.

61. Cong YS, Wen J and Bacchetti S: The human telomerase catalytic subunit hTERT: Organization of the gene and characterization of the promoter. Hum Mol Genet 8: 137-142, 1999.

62. Lee DD, Leão R, Komosa M, Gallo M, Zhang CH, Lipman T, Remke M, Heidari A, Nunes NM, Apolónio JD, et al: DNA hypermethylation within TERT promoter upregulates TERT expression in cancer. J Clin Invest 129: 223-229, 2019

63. Casillas MA, Brotherton SL, Andrews LG, Ruppert JM and Tollefsbol TO: Induction of endogenous telomerase (hTERT) by c-Myc in WI-38 fibroblasts transformed with specific genetic elements. Gene 316: 57-65, 2003.

64. Bellon M and Nicot C: Regulation of telomerase and telomeres: Human tumor viruses take control. J Natl Cancer Inst 100: 98-108, 2008

65. Barthel FP, Wei W, Tang M, Martinez-Ledesma E, Hu X, Amin SB, Akdemir KC, Seth S, Song X, Wang Q, et al: Systematic analysis of telomere length and somatic alterations in 31 cancer types. Nat Genet 49: 349-357, 2017.

66. Killela PJ, Reitman ZJ, Jiao Y, Bettegowda C, Agrawal N, Diaz LA Jr, Friedman AH, Friedman H, Gallia GL, Giovanella BC, et al: TERT promoter mutations occur frequently in gliomas and a subset of tumors derived from cells with low rates of self-renewal. Proc Natl Acad Sci USA 110: 6021-6026, 2013.

67. Rachakonda PS, Hosen I, de Verdier PJ, Fallah M, Heidenreich B, Ryk C, Wiklund NP, Steineck G, Schadendorf D, Hemminki K and Kumar R: TERT promoter mutations in bladder cancer affect patient survival and disease recurrence through modification by a common polymorphism. Proc Natl Acad Sci USA 110: 17426-17431, 2013. 
68. Wang K, Liu T, Liu L, Liu J, Liu C, Wang C, Ge N, Ren H, Yan K, $\mathrm{Hu}$, et al: TERT promoter mutations in renal cell carcinomas and upper tract urothelial carcinomas. Oncotarget 5: 1829-1836, 2014.

69. Cevik D, Yildiz G and Ozturk M: Common telomerase reverse transcriptase promoter mutations in hepatocellular carcinomas from different geographical locations. World J Gastroenterol 21: 311-317, 2015.

70. Liu X, Bishop J, Shan Y, Pai S, Liu D, Murugan AK, Sun H, El-Naggar AK and Xing M: Highly prevalent TERT promoter mutations in aggressive thyroid cancers. Endocr Relat Cancer 20: 603-610, 2013.

71. Koelsche C, Renner M, Hartmann W, Brandt R, Lehner B, Waldburger N, Alldinger I, Schmitt T, Egerer G, Penzel R, et al: TERT promoter hotspot mutations are recurrent in myxoid liposarcomas but rare in other soft tissue sarcoma entities. J Exp Clin Cancer Res 33: 33, 2014.

72. Vinagre J, Pinto V, Celestino R, Reis M, Pópulo H, Boaventura P, Melo M, Catarino T, Lima J, Lopes JM, et al: Telomerase promoter mutations in cancer: An emerging molecular biomarker? Virchows Arch 465: 119-133, 2014.

73. Bell RJA, Rube HT, Kreig A, Mancini A, Fouse SD, Nagarajan RP, Choi S, Hong C, He D, Pekmezci M, et al: Cancer. The transcription factor GABP selectively binds and activates the mutant TERT promoter in cancer. Science 348: 1036-1039, 2015.

74. Chen X, Kost J, Sulovari A, Wong N, Liang WS, Cao J and Li D: A virome-wide clonal integration analysis platform for discovering cancer viral etiology. Genome Res 29: 819-830, 2019.

75. Stråăt K, Liu C, Rahbar A, Zhu Q, Liu L, Wolmer-Solberg N, Lou F, Liu Z, Shen J, Jia J, et al: Activation of telomerase by human cytomegalovirus. J Natl Cancer Inst 101: 488-497, 2009.

76. Labgaa I, Villacorta-Martin C, D'Avola D, Craig AJ, von Felden J, Martins-Filho SN, Sia D, Stueck A, Ward SC and Fiel MI: A pilot study of ultra-deep targeted sequencing of plasma DNA identifies driver mutations in hepatocellular carcinoma. Oncogene 37: 3740-3752, 2018.

77. Hurst CD, Platt FM and Knowles MA: Comprehensive mutation analysis of the TERT promoter in bladder cancer and detection of mutations in voided urine. Eur Urol 65: 367-369, 2014

78. Juratli TA, Stasik S, Zolal A, Schuster C, Richter S, Daubner D, Juratli MA, Thowe R, Hennig S, Makina M, et al: TERT promoter mutation detection in cell-free tumor-derived DNA in patients with IDH wild-type glioblastomas: A pilot prospective study. Clin Cancer Res 24: 5282-5291, 2018.

79. Liu L, Liu C, Fotouhi O, Fan Y, Wang K, Xia C, Shi B, Zhang G, Wang K, Kong F, et al: TERT promoter hypermethylation in gastrointestinal cancer: A potential stool biomarker. Oncologist 22: 1178-1188, 2017.

80. Bougel S, Lhermitte B, Gallagher G, de Flaugergues JC, Janzer RC and Benhattar J: Methylation of the hTERT promoter: A novel cancer biomarker for leptomeningeal metastasis detection in cerebrospinal fluids. Clin Cancer Res 19: 2216-2223, 2013

81. Bianchi F, Nicassio F, Marzi M, Belloni E, Dall'olio V, Bernard L, Pelosi G, Maisonneuve P, Veronesi G and Di Fiore PP: A serum circulating miRNA diagnostic test to identify asymptomatic high-risk individuals with early stage lung cancer. EMBO Mol Med 3: 495-503, 2011.

82. Nagore E, Heidenreich B, Rachakonda S, Garcia-Casado Z, Requena C, Soriano V, Frank C, Traves V, Quecedo E, Sanjuan-Gimenez J, et al: TERT promoter mutations in melanoma survival. Int J Cancer 139: 75-84, 2016.

83. Yuan Y, Qi C, Maling G, Xiang W, Yanhui L, Ruofei L, Yunhe M, Jiewen $\mathrm{L}$ and Qing M: TERT mutation in glioma: Frequency, prognosis and risk. J Clin Neurosci 26: 57-62, 2016.

84. Melo M, da Rocha AG, Vinagre J, Batista R, Peixoto J, Tavares C, Celestino R, Almeida A, Salgado C, Eloy C, et al: TERT promoter mutations are a major indicator of poor outcome in differentiated thyroid carcinomas. J Clin Endocrinol Metab 99: E754-765, 2014

85. Liu R and Xing M: TERT promoter mutations in thyroid cancer. Endocr Relat Cancer 23: R143-R155, 2016

86. Castelo-Branco P, Choufani S, Mack S, Gallagher D, Zhang C, Lipman T, Zhukova N, Walker EJ, Martin D, Merino D, et al Methylation of the TERT promoter and risk stratification of childhood brain tumours: An integrative genomic and molecular study. Lancet Oncol 14: 534-542, 2013.
87. Svahn F, Paulsson JO, Stenman A, Fotouhi O, Mu N, Murtha TD, Korah R, Carling T, Bäckdahl M, Wang N, et al: TERT promoter hypermethylation is associated with poor prognosis in adrenocortical carcinoma. Int J Mol Med 42: 1675-1683, 2018.

88. Liu X, Qu S, Liu R, Sheng C, Shi X, Zhu G, Murugan AK, Guan $\mathrm{H}, \mathrm{Yu} \mathrm{H}$, Wang Y, et al: TERT promoter mutations and their association with BRAF V600E mutation and aggressive clinicopathological characteristics of thyroid cancer. J Clin Endocrinol Metab 99: E1130-E1136, 2014.

89. Macerola E, Loggini B, Giannini R, Garavello G, Giordano M, Proietti A, Niccoli C, Basolo F and Fontanini G: Coexistence of TERT promoter and BRAF mutations in cutaneous melanoma is associated with more clinicopathological features of aggressiveness. Virchows Arch 467: 177-184, 2015.

90. Liu R, Zhang T, Zhu G and Xing M: Regulation of mutant TERT by BRAF V600E/MAP kinase pathway through FOS/GABP in human cancer. Nat Commun 9: 579, 2018.

91. Liu W, Yin Y, Wang J, Shi B, Zhang L, Qian D, Li C, Zhang H, Wang S, Zhu J, et al: Kras mutations increase telomerase activity and targeting telomerase is a promising therapeutic strategy for Kras-mutant NSCLC. Oncotarget 8: 179-190, 2017.

92. Meeker AK, Hicks JL, Platz EA, March GE, Bennett CJ, Delannoy MJ and De Marzo AM: Telomere shortening is an early somatic DNA alteration in human prostate tumorigenesis. Cancer Res 62: 6405-6409, 2002.

93. Pestana A, Vinagre J, Sobrinho-Simões M and Soares P: TERT biology and function in cancer: Beyond immortalisation. J Mol Endocrinol 58: R129-R146, 2017.

94. Frink RE, Peyton M, Schiller JH, Gazdar AF, Shay JW and Minna JD: Telomerase inhibitor imetelstat has preclinical activity across the spectrum of non-small cell lung cancer oncogenotypes in a telomere length dependent manner. Oncotarget 7: 31639-31651, 2016.

95. Chiappori AA, Kolevska T, Spigel DR, Hager S, Rarick M, Gadgeel S, Blais N, Von Pawel J, Hart L, Reck M, et al: A randomized phase II study of the telomerase inhibitor imetelstat as maintenance therapy for advanced non-small-cell lung cancer. Ann Oncol 26: 354-362, 2015

96. Burchett KM, Yan Y and Ouellette MM: Telomerase inhibitor Imetelstat (GRN163L) limits the lifespan of human pancreatic cancer cells. PLoS One 9: e85155, 2014.

97. Shammas MA, Koley H, Bertheau RC, Neri P, Fulciniti M, Tassone P, Blotta S, Protopopov A, Mitsiades C, Batchu RB, et al: Telomerase inhibitor GRN163L inhibits myeloma cell growth in vitro and in vivo. Leukemia 22: 1410-1418, 2008.

98. Dikmen ZG, Gellert GC, Jackson S, Gryaznov S, Tressler R, Dogan P, Wright WE and Shay JW: In vivo inhibition of lung cancer by GRN163L: A novel human telomerase inhibitor. Cancer Res 65: 7866-7873, 2005.

99. Tokcaer-Keskin Z, Dikmen ZG, Ayaloglu-Butun F, Gultekin S, Gryaznov SM and Akcali KC: The effect of telomerase template antagonist GRN163L on bone-marrow-derived rat mesenchymal stem cells is reversible and associated with altered expression of cyclin d1, cdk4 and cdk6. Stem Cell Rev Rep 6: 224-233, 2010.

100. Burchett KM, Etekpo A, Batra SK, Yan Y and Ouellette MM: Inhibitors of telomerase and poly(ADP-ribose) polymerases synergize to limit the lifespan of pancreatic cancer cells. Oncotarget 8: 83754-83767, 2017

101. Koziel JE and Herbert BS: The telomerase inhibitor imetelstat alone, and in combination with trastuzumab, decreases the cancer stem cell population and self-renewal of HER2+ breast cancer cells. Breast Cancer Res Treat 149: 607-618, 2015

102. Wu X, Zhang J, Yang S, Kuang Z, Tan G, Yang G, Wei Q and Guo Z: Telomerase antagonist imetelstat increases radiation sensitivity in esophageal squamous cell carcinoma. Oncotarget 8: 13600-13619, 2017.

103. Chhabra G, Wojdyla L, Frakes M, Schrank Z, Leviskas B, Ivancich M, Vinay P, Ganapathy R, Ramirez BE and Puri N: Mechanism of action of G-quadruplex-forming oligonucleotide homologous to the telomere overhang in melanoma. J Invest Dermatol 138: 903-910, 2018.

104. Schrank Z, Khan N, Osude C, Singh S, Miller RJ, Merrick C, Mabel A, Kuckovic A and Puri N: Oligonucleotides targeting telomeres and telomerase in cancer. Molecules 23: pii: E2267, 2018.

105. Pitman RT, Wojdyla L and Puri N: Mechanism of DNA damage responses induced by exposure to an oligonucleotide homologous to the telomere overhang in melanoma. Oncotarget 4: 761-771, 2013 
106. Puri N, Pitman RT, Mulnix RE, Erickson T, Iness AN, Vitali C, Zhao Y and Salgia R: Non-small cell lung cancer is susceptible to induction of DNA damage responses and inhibition of angiogenesis by telomere overhang oligonucleotides. Cancer Lett 343: 14-23, 2014.

107. Wojdyla L, Stone AL, Sethakorn N, Uppada SB, Devito JT, Bissonnette $\mathrm{M}$ and Puri N: T-oligo as an anticancer agent in colorectal cancer. Biochem Biophys Res Commun 446: 596-601, 2014.

108. Weng D, Cunin MC, Song B, Price BD, Eller MS, Gilchrest BA, Calderwood SK and Gong J: Radiosensitization of mammary carcinoma cells by telomere homolog oligonucleotide pretreatment. Breast Cancer Res 12: R71, 2010.

109. Guzman H, Sanders K, Idica A, Bochnakian A, Jury D, Daugaard I, Zisoulis DG and Pedersen IM: miR-128 inhibits telomerase activity by targeting TERT mRNA. Oncotarget 9 : 13244-13253, 2018

110. Zhou N, Fei D, Zong S, Zhang M and Yue Y: MicroRNA-138 inhibits proliferation, migration and invasion through targeting hTERT in cervical cancer. Oncol Lett 12: 3633-3639, 2016.

111. Mitomo S, Maesawa C, Ogasawara S, Iwaya T, Shibazaki M, Yashima-Abo A, Kotani K, Oikawa H, Sakurai E, Izutsu N, et al: Downregulation of miR-138 is associated with overexpression of human telomerase reverse transcriptase protein in human anaplastic thyroid carcinoma cell lines. Cancer Sci 99: 280-286, 2008.

112. Zhang D, Xiao YF, Zhang JW, Xie R, Hu CJ, Tang B, Wang SM, $\mathrm{Wu}$ YY, Hao NB and Yang SM: miR-1182 attenuates gastric cancer proliferation and metastasis by targeting the open reading frame of hTERT. Cancer Lett 360: 151-159, 2015.

113. Melnik BC: miR-21: An environmental driver of malignant melanoma? J Transl Med 13: 202, 2015.

114. Yang Y, Yang JJ, Tao H and Jin WS: MicroRNA-21 controls hTERT via PTEN in human colorectal cancer cell proliferation. J Physiol Biochem 71: 59-68, 2015.

115. Nguyen DD and Chang S: Development of novel therapeutic agents by inhibition of oncogenic microRNAs. Int J Mol Sci 19: pii: E65, 2017

116. Mizukoshi E and Kaneko S: Telomerase-targeted cancer immunotherapy. Int J Mol Sci 20: pii: E1823, 2019.

117. Staff C, Mozaffari F, Frödin JE, Mellstedt $\mathrm{H}$ and Liljefors M: Telomerase (GV1001) vaccination together with gemcitabine in advanced pancreatic cancer patients. Int J Oncol 45: 1293-1303, 2014.

118. Fenoglio D, Traverso P, Parodi A, Tomasello L, Negrini S, Kalli F, Battaglia F, Ferrera F, Sciallero S, Murdaca G, et al: A multi-peptide, dual-adjuvant telomerase vaccine (GX301) is highly immunogenic in patients with prostate and renal cancer. Cancer Immunol Immunother 62: 1041-1052, 2013

119. Fenoglio D, Parodi A, Lavieri R, Kalli F, Ferrera F, Tagliamacco A, Guastalla A, Lamperti MG, Giacomini M and Filaci G: Immunogenicity of GX301 cancer vaccine: Four (telomerase peptides) are better than one. Hum Vaccin Immunother 11: 838-850, 2015.

120.Lilleby W, Gaudernack G, Brunsvig PF, Vlatkovic L, Schulz M, Mills K, Hole KH and Inderberg EM: Phase I/IIa clinical trial of a novel hTERT peptide vaccine in men with metastatic hormone-naive prostate cancer. Cancer Immunol Immunother 66: 891-901, 2017.

121. Kotsakis A, Papadimitraki E, Vetsika EK, Aggouraki D, Dermitzaki EK, Hatzidaki D, Kentepozidis N, Mavroudis D and Georgoulias V: A phase II trial evaluating the clinical and immunologic response of HLA-A2(+) non-small cell lung cancer patients vaccinated with an hTERT cryptic peptide. Lung Cancer 86: 59-66, 2014.

122. Su Z, Dannull J, Yang BK, Dahm P, Coleman D, Yancey D, Sichi S, Niedzwiecki D, Boczkowski D, Gilboa E and Vieweg J: Telomerase mRNA-transfected dendritic cells stimulate antigen-specific CD8+ and CD4+ T cell responses in patients with metastatic prostate cancer. J Immunol 174: 3798-3807, 2005.
123. Khoury HJ, Collins RH Jr, Blum W, Stiff PS, Elias L, Lebkowski JS, Reddy A, Nishimoto KP, Sen D, Wirth ED III, et al: Immune responses and long-term disease recurrence status after telomerase-based dendritic cell immunotherapy in patients with acute myeloid leukemia. Cancer 123: 3061-3072, 2017.

124. Galati D and Zanotta S: Empowering dendritic cell cancer vaccination: The role of combinatorial strategies. Cytotherapy 20: 1309-1323, 2018.

125. Salazar-Onfray F, Pereda C, Reyes D and López MN: TAPCells, the Chilean dendritic cell vaccine against melanoma and prostate cancer. Biol Res 46: 431-440, 2013

126. Thalmensi J,Pliquet E, Liard C, Escande M, Bestetti T, Julithe M, Kostrzak A, Pailhes-Jimenez AS, Bourges E, Loustau M, et al: Anticancer DNA vaccine based on human telomerase reverse transcriptase generates a strong and specific $\mathrm{T}$ cell immune response. Oncoimmunology 5: e1083670, 2016.

127. Yan J, Pankhong P, Shin TH, Obeng-Adjei N, Morrow MP, Walters JN, Khan AS, Sardesai NY and Weiner DB: Highly optimized DNA vaccine targeting human telomerase reverse transcriptase stimulates potent antitumor immunity. Cancer Immunol Res 1: 179-189, 2013.

128. Ohta R, Demachi-Okamura A, Akatsuka Y, Fujiwara H and Kuzushima K: Improving TCR affinity on 293T cells. J Immunol Methods 466: 1-8, 2019.

129. Jordheim LP, Durantel D, Zoulim F and Dumontet C: Advances in the development of nucleoside and nucleotide analogues for cancer and viral diseases. Nat Rev Drug Discov 12: 447-464, 2013.

130. Pascolo E, Wenz C, Lingner J, Hauel N, Priepke H, Kauffmann I, Garin-Chesa P, Rettig WJ, Damm K and Schnapp A: Mechanism of human telomerase inhibition by BIBR1532, a synthetic, non-nucleosidic drug candidate. J Biol Chem 277: 15566-15572, 2002.

131. Kim MY, Vankayalapati H, Shin-Ya K, Wierzba K and Hurley LH: Telomestatin, a potent telomerase inhibitor that interacts quite specifically with the human telomeric intramolecular g-quadruplex. J Am Chem Soc 124: 2098-2099, 2002.

132. Gomez DL, Armando RG, Cerrudo CS, Ghiringhelli PD and Gomez DE: Telomerase as a cancer target. Development of new molecules. Curr Top Med Chem 16: 2432-2440, 2016

133. Nemunaitis J, Tong AW, Nemunaitis M, Senzer N, Phadke AP, Bedell C, Adams N, Zhang YA, Maples PB, Chen S, et al: A phase I study of telomerase-specific replication competent oncolytic adenovirus (telomelysin) for various solid tumors. Mol Ther 18: 429-434, 2010.

134. Schepelmann S, Ogilvie LM, Hedley D, Friedlos F, Martin J, Scanlon I, Chen P, Marais R and Springer CJ: Suicide gene therapy of human colon carcinoma xenografts using an armed oncolytic adenovirus expressing carboxypeptidase G2. Cancer Res 67: 4949-4955, 2007.

135. Picard D: Intracellular dynamics of the Hsp90 co-chaperone p23 is dictated by Hsp90. Exp Cell Res 312: 198-204, 2006.

136. Ning X, Yang S, Wang R, Zhang R, Guo L, Tie J, Cheng Y, Wang G, Wan S and Fang D: POT1 deficiency alters telomere length and telomere-associated gene expression in human gastric cancer cells. Eur J Cancer Prev 19: 345-351, 2010.

137. Ganesan $\mathrm{K}$ and $\mathrm{Xu} \mathrm{B}$ : Telomerase inhibitors from natural products and their anticancer potential. Int J Mol Sci 19: pii: E13, 2017.

138. Mizushina Y, Takeuchi T, Sugawara F and Yoshida $\mathrm{H}$ : Anti-cancer targeting telomerase inhibitors: $\beta$-rubromycin and oleic acid. Mini Rev Med Chem 12: 1135-1143, 2012.

139. Smith S: Telomerase can't handle the stress. Genes Dev 32: 597-599, 2018.

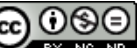

This work is licensed under a Creative Commons Attribution-NonCommercial-NoDerivatives 4.0 International (CC BY-NC-ND 4.0) License. 